\title{
Fractionated Gamma Knife radiosurgery for skull base meningiomas: a single-institution experience
}

\author{
Krishna C. Joshi, MBBS, MCh, ${ }^{1,3}$ Alankrita Raghavan, BA, ${ }^{2}$ Baha'eddin Muhsen, MD, ${ }^{1,3}$ \\ Jason Hsieh, MD, ${ }^{1}$ Hamid Borghei-Razavi, MD, ${ }^{1,3}$ Samuel T. Chao, MD, ,,4 Gene H. Barnett, MD,,3 \\ John H. Suh, MD, , ${ }^{3,4}$ Gennady Neyman, PhD, , ${ }^{3,4}$ Varun R. Kshettry, MD, ${ }^{1,3}$ Pablo F. Recinos, MD, ${ }^{1,3}$ \\ Alireza M. Mohammadi, MD, ${ }^{1,3}$ and Lilyana Angelov, MD ${ }^{1,3}$
}

${ }^{1}$ Department of Neurosurgery, Cleveland Clinic Lerner College of Medicine of Case Western Reserve University; ${ }^{2}$ Case Western Reserve University School of Medicine; ${ }^{2}$ Rose Ella Burkhardt Brain Tumor and Neuro-Oncology Center, Neurological Institute; and ${ }^{4}$ Department of Radiation Oncology, Taussig Cancer Institute, Cleveland Clinic, Cleveland, Ohio

\begin{abstract}
OBJECTIVE Gamma Knife radiosurgery (GKRS) has been successfully used for the treatment of intracranial meningiomas given its steep dose gradients and high-dose conformality. However, treatment of skull base meningiomas (SBMs) may pose significant risk to adjacent radiation-sensitive structures such as the cranial nerves. Fractionated GKRS (fGKRS) may decrease this risk, but until recently it has not been practical with traditional pin-based systems. This study reports the authors' experience in treating SBMs with fGKRS, using a relocatable, noninvasive immobilization system.

METHODS The authors performed a retrospective review of all patients who underwent fGKRS for SBMs between 2013 and 2018 delivered using the Extend relocatable frame system or the Icon system. Patient demographics, pre- and post-GKRS tumor characteristics, perilesional edema, prior treatment details, and clinical symptoms were evaluated. Volumetric analysis of pre-GKRS, post-GKRS, and subsequent follow-up visits was performed.
\end{abstract}

RESULTS Twenty-five patients met inclusion criteria. Nineteen patients were treated with the Icon system, and 6 patients were treated with the Extend system. The mean pre-fGKRS tumor volume was $7.62 \mathrm{~cm}^{3}$ (range 4.57-13.07 $\left.\mathrm{cm}^{3}\right)$. The median margin dose was 25 Gy delivered in $4(8 \%)$ or $5(92 \%)$ fractions. The median follow-up time was 12.4 months (range 4.7-17.4 months). Two patients (9\%) experienced new-onset cranial neuropathy at the first follow-up. The mean postoperative tumor volume reduction was $15.9 \%$ with 6 patients $(27 \%)$ experiencing improvement of cranial neuropathy at the first follow-up. Median first follow-up scans were obtained at 3.4 months (range 2.8-4.3 months). Three patients $(12 \%)$ developed asymptomatic, mild perilesional edema by the first follow-up, which remained stable subsequently.

CONCLUSIONS fGKRS with relocatable, noninvasive immobilization systems is well tolerated in patients with SBMs and demonstrated satisfactory tumor control as well as limited radiation toxicity. Future prospective studies with longterm follow-up and comparison to single-session GKRS or fractionated stereotactic radiotherapy are necessary to validate these findings and determine the efficacy of this approach in the management of SBMs.

https://thejns.org/doi/abs/10.3171/2019.3.FOCUS1963

KEYWORDS Gamma Knife radiosurgery; fractionated radiosurgery; meningioma; skull base

$\mathrm{S}$ KULL base meningiomas (SBMs) account for up to $40 \%$ of intracranial meningiomas and can cause significant morbidity due to their location and size..$^{8,46}$ SBMs in particular can cause cranial nerve compression and therefore lead to debilitating symptoms. Management of SBMs can include observation, resection, and radiosur- gery or radiation therapy. Due to the lesion's proximity to neurovascular structures, complete resection of SBMs is challenging and difficult to achieve. ${ }^{38}$ Consequently, radiosurgery is increasingly used in the treatment of these tumors and has proved to be safe and effective as primary and adjuvant treatment. ${ }^{36,44}$

ABBREVIATIONS CBCT = cone-beam CT; CTCAE = Common Terminology Criteria for Adverse Events; fGKRS = fractionated Gamma Knife radiosurgery; GKRS = Gamma Knife radiosurgery; KPS = Karnofsky Performance Scale; PLE = perilesional edema; SBM = skull base meningioma.

SUBMITTED January 31, 2019. ACCEPTED March 28, 2019

INCLUDE WHEN CITING DOI: 10.3171/2019.3.FOCUS1963. 
Gamma Knife radiosurgery (GKRS) dose distributions have steep dose gradients and high-dose conformality allowing for excellent target coverage and avoidance of nearby structures at risk. ${ }^{32}$ However, it may pose significant risk to adjacent radiation-sensitive structures such as the optic nerves and brainstem. It can also be challenging to deliver the optimal treatment dose to large-volume tumors $\left(>10 \mathrm{~cm}^{3}\right)$. The deleterious effects can be due to either the direct effect of radiation, as with radiation necrosis, or development of posttreatment edema. Fractionated radiosurgery (delivered in 2-5 fractions) may potentially overcome these limitations for targets located close to critical structures like the optic pathway or for treatment of large tumor volumes given the time allowed for repair between fractions, which permits the delivery of a higher dose with acceptable toxicity. ${ }^{1,16}$ However, it is important to note that unlike linear accelerator systems, GKRS is naturally hot (as the isodose line is between 50\% and 58\%), so understanding the safety and efficacy is particularly relevant in spite of other experiences using fractionated radiosurgery with the linear accelerator.

Until recently, fractionated GKRS (fGKRS) was not practical since it required a patient to have the head frame affixed for several days during treatment or serial head frame placements along with new imaging for each successive placement of the frame. The development of the Gamma Knife Extend system and the more recent development of the Icon system (both developed by Elekta AB) have made fGKRS possible and straightforward. ${ }^{32}$ To the best of our knowledge, there are only 4 institutional experiences previously published that describe this technique. ${ }^{10,18,32,36}$ We present a retrospective review of 25 cases of SBM treated with fGKRS: 6 patients treated with the Extend system and 19 patients with the Icon system. This article presents the unique experience of using fGKRS in cases of SBM and represents the largest experience to date of using the Icon system.

\section{Methods \\ Clinical Data Collection}

This was an IRB-approved retrospective chart review evaluating patients with SBMs who underwent fGKRS at our institution. We identified 25 patients treated from 2013 to 2018. Patients were included if they were $>18$ years of age and had an SBM treated upfront by fGKRS or following subtotal resection. Patients who had at least one clinical and radiological follow-up visit after the GKRS were included in the study. The diagnosis of SBM was made based on the radiographic features and/or from the histopathological findings from the previously resected lesion. Patients were considered for fGKRS because of the lesion's proximity to eloquent structures, such as the optic nerve or brainstem, or because of the large size of the lesion (>2.5 $\mathrm{cm}$ in diameter).

The following data were obtained from the medical records: patient demographics, clinical presentation, Karnofsky Performance Scale (KPS) score, history of previous surgery or radiation therapy, dates of the first 3 followup visits after fGKRS, and date of the final follow-up. Lesion characteristics, including location, volume (in $\mathrm{cm}^{3}$ ), and degree of perilesional edema (PLE), were recorded (Table 1). Radiosurgical parameters, including prescribed dose, isodose line, conformity index, number of fractions, and maximum dose, were noted (Table 2). Pre- and postGKRS volumetric measurements of the tumor were performed using gadolinium-enhanced T1-weighted MRI sequences using Brainlab software (iPlan Net 3.6.0), and PLE was assessed using T2-weighted FLAIR sequences. The tumors were considered stable if the change in volume was less than $5 \%$ of the original volume, and they were considered to be progressed/reduced if they increased/decreased by more than 5\%, respectively. The degree of PLE before and after fGKRS was classified using a five-step scoring system (Table 3).

\section{Radiosurgical Technique}

All patients underwent a preliminary preprocedural evaluation by a neurosurgeon and radiation oncologist to determine appropriateness for fGKRS and were subsequently treated under the care of a neurosurgeon, radiation oncologist, and medical physicist. Our methodologies for using the Extend relocatable frame system are consistent with those previously described in the literature ${ }^{37}$ Briefly, a vacuum spacer is fitted and filled with dental impression material to create a mold. Initial patient setup and verification are performed on the Gamma Knife Perfexion using the reposition check tool and measurement probes, before and after acquisition of the stereotactic CT scan, which is coregistered with a volumetric MR image (which is usually acquired a few days before the treatment), and planning is performed on GammaPlan (Elekta AB).

The Leksell Gamma Knife Icon was introduced in 2015 and was installed at our institution in March 2017. Details regarding the procedure used to apply the Icon system are consistent with those previously described in the literature. ${ }^{43}$ Briefly, a pretreatment thermoplastic mask is made by the radiation therapist. Once the mask is ready, a cone-beam CT (CBCT) scan is acquired after the mask is secured to the patient. The patients also had a 1-mm resolution contrast-enhanced MR image without the mask, which was transferred to GammaPlan for preplanning as long as there were no contraindications to MRI. The gross tumor volumes were initially contoured on this MRI and when the stereotactic CT was obtained, the image data sets were coregistered and the preplanned treatment plan was further coregistered to the CBCT scan. Prior to each fraction, CBCT was performed to verify the actual skull position. Automatic coregistration was performed to determine the daily shift in translation and rotation. The program automatically adapted the shot positions to the daily position and recalculated the dose distribution (online adaptive planning). The daily difference between the adapted and initial plan was analyzed and approved by a physician and a medical physicist.

Multiple isocenter plans were created for each tumor. The radiation oncologist typically prescribed 5 daily fractions of 5 Gy each, as used in previous studies ${ }^{31,35}$ (Fig. 1). The maximum point dose constraint (defined to the $0.035-\mathrm{cm}^{3}$ volume) to adjacent critical structures was decided based on previously published guidelines (25 Gy for optic pathway and 31 Gy for brainstem when treating in 5 
TABLE 1. Baseline demographic data, clinical data, and treatment parameters

\begin{tabular}{|c|c|}
\hline Parameter & Value \\
\hline Age, years* & $66.2(10.8)$ \\
\hline Female† & $20(80)$ \\
\hline \multicolumn{2}{|l|}{ Tumor location† } \\
\hline Tentorial & $2(8)$ \\
\hline Petroclival & $5(20)$ \\
\hline Cerebellopontine angle & $5(20)$ \\
\hline Clinoidal & $5(20)$ \\
\hline Cavernous sinus & $5(20)$ \\
\hline Other $\ddagger$ & $3(12)$ \\
\hline \multicolumn{2}{|l|}{ Grade of PLE (see Table 3)† } \\
\hline 0 & $21(84)$ \\
\hline 1 & $2(8)$ \\
\hline 2 & $2(8)$ \\
\hline 3,4 & $0(0)$ \\
\hline \multicolumn{2}{|c|}{ Preradiosurgical clinical symptoms $†$} \\
\hline Headache & $3(12)$ \\
\hline Weakness & $2(8)$ \\
\hline Cranial nerve deficit & $17(68)$ \\
\hline Memory/cognitive changes & $1(4)$ \\
\hline \multicolumn{2}{|l|}{ Cranial neuropathy $\dagger$} \\
\hline$\|$ & $2(8)$ \\
\hline III & $5(20)$ \\
\hline IV & $1(4)$ \\
\hline $\mathrm{V}$ & $5(20)$ \\
\hline $\mathrm{VI}$ & $3(12)$ \\
\hline VII, VIII & $6(24)$ \\
\hline$I X, X, X \mid$ & $0(0)$ \\
\hline XII & $0(0)$ \\
\hline Previous surgery $\dagger$ & $12(48)$ \\
\hline Simpson grade I & $1(11)$ \\
\hline Simpson grade II & $1(11)$ \\
\hline Simpson grade III & $1(11)$ \\
\hline Simpson grade IV & $6(67)$ \\
\hline Simpson grade V & $0(0)$ \\
\hline \multicolumn{2}{|l|}{ WHO grade $\dagger$} \\
\hline Grade I & $10(91)$ \\
\hline Grade II & $1(9)$ \\
\hline Grade III & $0(0)$ \\
\hline Prior radiation $†$ & $4(16)$ \\
\hline GKRS & $2(50)$ \\
\hline EBRT & $2(50)$ \\
\hline Median follow-up (mos)§ & $12.4(4.7-17.4)$ \\
\hline No. of follow-up visits* & $2(1.3)$ \\
\hline
\end{tabular}

EBRT = external-beam radiotherapy.

* Values are presented as the mean (SD).

$\dagger$ Values are presented as the number (\%).

$\ddagger$ Other locations include one tumor each in the supraorbital, pineal, and cribriform plate region.

$\S$ Values are presented as median (range).
TABLE 2. Radiosurgical treatment parameters

\begin{tabular}{|c|c|}
\hline Parameter & Value \\
\hline \multicolumn{2}{|l|}{ Immobilization device used ${ }^{*}$} \\
\hline Extend & $6(24)$ \\
\hline Icon & $19(76)$ \\
\hline \multicolumn{2}{|l|}{ Treatment parameters } \\
\hline \multicolumn{2}{|l|}{ Margin dose* } \\
\hline $25 \mathrm{~Gy}$ & $23(92)$ \\
\hline $24 \mathrm{~Gy}$ & $2(8)$ \\
\hline Conformality index $†$ & $1.5(1.37-1.62)$ \\
\hline Isodose line (\%)† & $55(50-58)$ \\
\hline Maximum dose to target in Gy† & $46.3(24.5-50.6)$ \\
\hline Homogeneity index $\dagger$ & $1.85(0.9-2.024)$ \\
\hline Gradient index $\uparrow$ & $2.8(2.6-3.72)$ \\
\hline \multicolumn{2}{|l|}{ No. of fractions* } \\
\hline 4 & $2(8)$ \\
\hline 5 & $23(92)$ \\
\hline \multicolumn{2}{|c|}{ Max pointł dose to adjacent critical structures in Gy† } \\
\hline Optic pathway & $12.5(3-17.5)$ \\
\hline Brainstem & $24.45(0.04-29)$ \\
\hline
\end{tabular}

* Values are presented as the number (\%) of patients.

$\dagger$ Values are presented as the median (IQR).

$\ddagger$ Defined as $<0.035 \mathrm{~cm}^{3}$.

TABLE 3. Degrees of PLE observed on pre-GKRS, post-GKRS, and subsequent follow-up MR images

\begin{tabular}{cl}
\hline Score & \multicolumn{1}{c}{ Definition } \\
\hline 0 & No evidence of PLE \\
\hline 1 & Max distance of edema $\leq 0.5 \mathrm{~mm}$ from edge of the lesion \\
\hline 2 & $\begin{array}{c}\text { Max distance of edema }>0.5 \mathrm{~mm} \text { to } \leq 20 \mathrm{~mm} \text { from edge of the } \\
\text { lesion }\end{array}$ \\
\hline 3 & $\begin{array}{c}\text { Max distance of edema }>20 \mathrm{~mm} \text {, or compression of ipsilat } \\
\text { ventricle }\end{array}$ \\
\hline 4 & Evidence of hydrocephalus or herniation \\
\hline
\end{tabular}

fractions). ${ }^{2}$ Tumor contours at the time of treatment and at 12-month follow-up are shown in Fig. 1.

\section{Radiological and Clinical Follow-Up}

After treatment, patients were clinically evaluated by the radiation oncologist and neurosurgeon in most cases at 3,6 , and 12 months and then yearly thereafter unless otherwise clinically indicated. Imaging follow-up with MRI was routinely performed at each visit. Follow-up data were collected by review of the patient's electronic medical records. The first 3 follow-up visits and the final follow-up visit were considered for each patient. Pre-fGKRS and post-fGKRS volumetric assessments of the tumor were performed using gadolinium-enhanced T1-weighted MRI sequences using the contouring tool on Brainlab software (iPlan Net 3.6.0). The adverse radiation effects were 


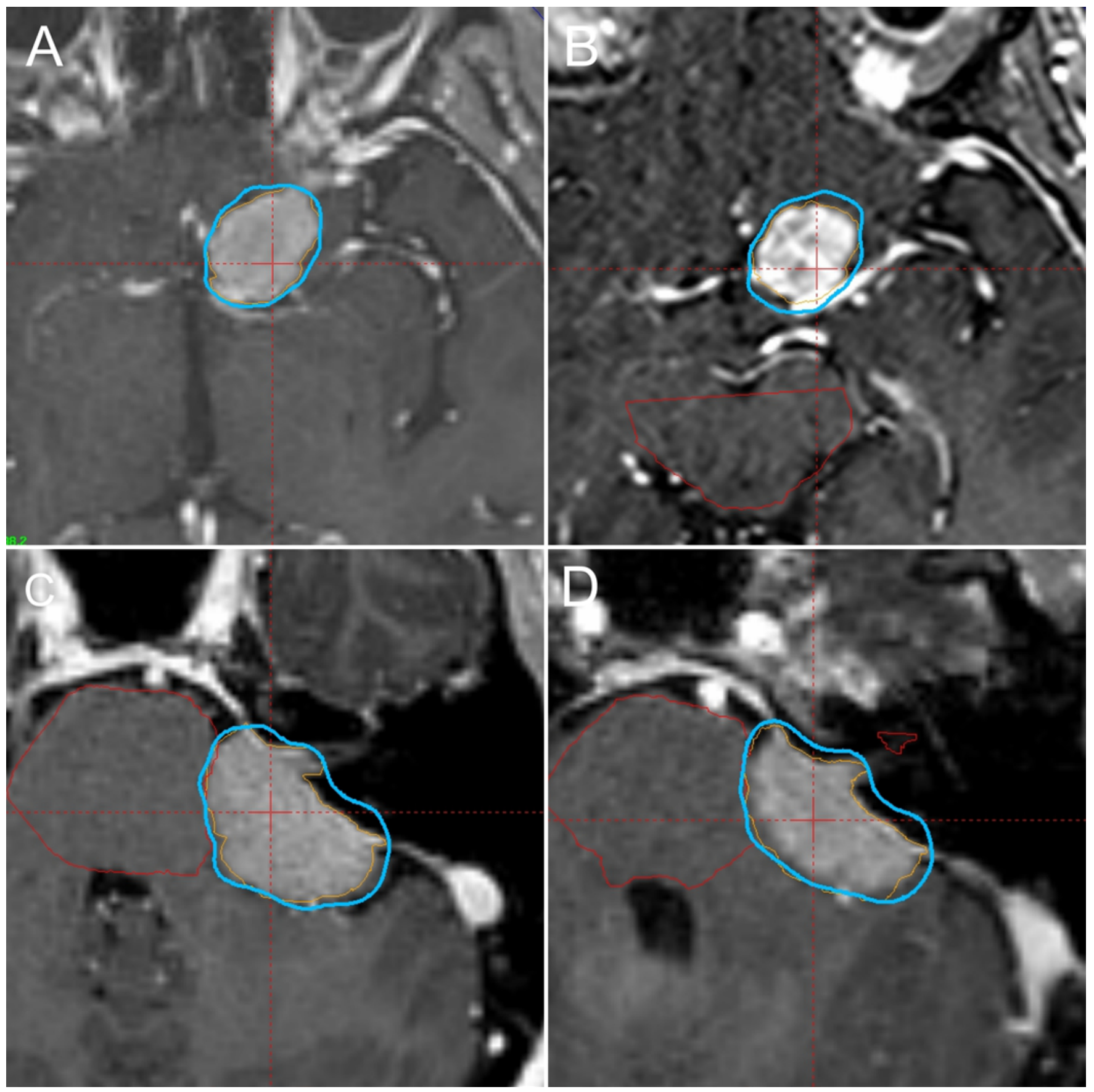

FIG. 1. MR images of a left medial clinoidal meningioma before treatment $\left(\mathbf{A}, 2.97 \mathrm{~cm}^{3}\right)$ and 12 months after treatment $(\mathbf{B}, 2.30$ $\left.\mathrm{cm}^{3}\right)$, and MR images of a left cerebellopontine angle meningioma before treatment $\left(\mathbf{C}, 9.36 \mathrm{~cm}^{3}\right)$ and 12 months after treatment $\left(\mathrm{D}, 7.88 \mathrm{~cm}^{3}\right.$ ). Both tumors were treated to a total dose of $25 \mathrm{~Gy}$ in 5 fractions.

graded using Common Terminology Criteria for Adverse Events (CTCAE) Version 5.0.

\section{Statistical Analysis}

Basic descriptive statistics were calculated as number (frequency), mean (standard deviation), and median (interquartile range or range), as appropriate. For data that appeared normally distributed, the mean was used, while otherwise the median was used. Kaplan-Meier curves were generated for progression-free survival.

\section{Results}

We collected data on 25 patients who underwent fGKRS for SBM. Of these, 1 patient was excluded from all analy- 
TABLE 4. Change in tumor volume and KPS in subsequent follow-up

\begin{tabular}{|c|c|}
\hline Factor & Value \\
\hline \multicolumn{2}{|l|}{ Pretreatment $(n=22)^{*}$} \\
\hline Tumor volume in $\mathrm{cm}^{3}$ & $7.62(4.57-13.07)$ \\
\hline KPS score & $90(80-100)$ \\
\hline \multicolumn{2}{|l|}{ 1st follow-up ( $n=22)$} \\
\hline Follow-up time in mos* & $3.8(2.8-4.3)$ \\
\hline Tumor volume in $\mathrm{cm}^{3 *}$ & $7.02(2.79-9.8)$ \\
\hline Change in volume† & $-15.9 \%(23.3 \%)$ \\
\hline KPS score* & $90(80-100)$ \\
\hline \multicolumn{2}{|l|}{ 2nd follow-up $(n=16)$} \\
\hline Follow-up time in mos, no. (\%)* & $9.3(7.4-12.4)$ \\
\hline Tumor volume in $\mathrm{cm}^{3 *}$ & $7.08(3.22-8.86)$ \\
\hline Change in volume (to last follow-up) $†$ & $-4.2 \%(9.6 \%)$ \\
\hline Change in volume (to baseline) $\dagger$ & $-20.9 \%(22.3 \%)$ \\
\hline KPS score ${ }^{*}$ & $90(70-100)$ \\
\hline \multicolumn{2}{|l|}{ 3rd follow-up $(n=10)$} \\
\hline Follow-up time in mos, no. $(\%)^{*}$ & $15.9(13.1-21.5)$ \\
\hline Tumor volume in $\mathrm{cm}^{3 *}$ & $6.25(4.94-8.80)$ \\
\hline Change in volume (to last follow-up) $†$ & $-1.9 \%(6.1 \%)$ \\
\hline Change in volume (to baseline) $\dagger$ & $-15.3 \%(20.0 \%)$ \\
\hline KPS score* & $90(70-100)$ \\
\hline \multicolumn{2}{|l|}{ Last follow-up (>3 mos follow-up, $n=4)^{*}$} \\
\hline Follow-up time in mos, no. (\%) & $42.6(30.9-46.7)$ \\
\hline Tumor volume in $\mathrm{cm}^{3}$ & $5.11(2.79-7.69)$ \\
\hline Change in volume (to 3rd follow-up) & $-11.2 \%(-26.2 \%$ to $-1.7 \%)$ \\
\hline Change in volume (to baseline) & $-30.0 \%(-39.3 \%$ to $-12.3 \%)$ \\
\hline KPS score & $90(80-100)$ \\
\hline Radiation toxicity, no. (\%) & $2(9)$ \\
\hline
\end{tabular}

* Values presented as the median (IQR).

$\dagger$ Values presented as the mean (SD).

ses for missing treatment data, and an additional 3 patients were excluded from all outcome analyses for having no follow-up data. The most common indications for fGKRS (as opposed to another modality of treatment) were proximity of the lesion to a critical structure, such as the optic apparatus, pituitary gland, or brainstem (59\%); large size $(40 \%)\left(>2.5 \mathrm{~cm}\right.$ in diameter or $\left.\geq 10 \mathrm{~cm}^{3}\right)$; failed previous radiation treatment (16\%); and involvement of the cavernous sinus $(6 \%)$ or extensive tumor involving the foramen magnum or the dorsum sella (6\%).

The mean age of patients was 66.2 years (range 55.477 years), and $80 \%$ were female. Tumors were most commonly located in the cerebellopontine angle, petroclival region, clinoid region, or involved the cavernous sinus (20\% each). The most common symptom was a cranial nerve deficit, which was present in $68 \%$ of patients. Nearly half $(48 \%)$ had previously undergone resection of their meningioma, and $91 \%$ had pathological findings consistent with WHO grade I meningioma. Of 9 patients whose surgical data were available, 6 had Simpson grade IV resection, while 1 patient each had Simpson grade I, II, and
TABLE 5. Frequency of cranial neuropathies among patients at each follow-up visit

\begin{tabular}{lc}
\hline \multicolumn{1}{c}{ Tumor Volume Change } & No. of Patients $(\%)$ \\
\hline Pretreatment $(\mathrm{n}=25)$ & $17(68 \%)$ \\
\hline Presence of any cranial neuropathy & $11(50 \%)$ \\
\hline 1st follow-up $(\mathrm{n}=22)$ & $2(9 \%)$ \\
\hline Presence of any cranial neuropathy & $6(27 \%)$ \\
\hline Development of new cranial neuropathy & \\
\hline Improvement in a cranial neuropathy & $9(56 \%)$ \\
\hline 2nd follow-up $(\mathrm{n}=16)$ & $1(6 \%)$ \\
\hline Presence of any cranial neuropathy & $2(13 \%)$ \\
\hline Development of new cranial neuropathy & $3(30 \%)$ \\
\hline Improvement in a cranial neuropathy & $1(10 \%)$ \\
\hline 3rd follow-up ( $\mathrm{n}=10)$ & $1(10 \%)$ \\
\hline Presence of any cranial neuropathy & \\
\hline Development of new cranial neuropathy & $0(0 \%)$ \\
\hline Improvement in a cranial neuropathy & $0(0 \%)$ \\
\hline Last follow-up (>3 follow-ups, $n=4)$ & $0(0 \%)$ \\
\hline Presence of any cranial neuropathy & \\
\hline Development of new cranial neuropathy & \\
\hline Improvement in a cranial neuropathy &
\end{tabular}

Patients at each follow-up visit who had a new cranial nerve neuropathy (even if they simultaneously had an improvement in another cranial neuropathy) were counted. Likewise, patients with resolution of a cranial nerve deficit, regardless of whether they simultaneously developed a new cranial nerve deficit, were counted.

III resections. Four patients (16\%) had prior radiotherapy or radiosurgery. We had data from a median of 2 follow-up visits and the median follow-up duration was 12.4 months. A summary of baseline demographic and clinical data can be found in Table 1.

The majority (76\%) of patients were treated using the Icon mask system, while the remainder were treated using the Extend system. Most patients (92\%) were treated in 5 fractions, while 2 patients $(8 \%)$ were treated in 4 fractions. A majority $(92 \%)$ of patients received 25 Gy to a median $55 \%$ isodose line with a median conformality index of 1.5 (Table 2). Two patients developed transient CTCAE grade 2 oculomotor paresis, which completely resolved in both cases over 3 months. Both of these patients received a Medrol Dosepak (which is $8 \mathrm{mg}$ of methylprednisone, started typically at $8 \mathrm{mg}$ three times a day and tapered over 1 week).

Outcome data were calculated for each follow-up visit up to the first 3 visits. For those who had additional followup beyond 3 visits, data from the most recent follow-up were also included for analysis. Patients had stable KPS scores at all follow-up visits and on average experienced a decrease in tumor volume that persisted throughout the follow-up period. Although a small fraction of patients developed a new cranial neuropathy during follow-up, a greater fraction of patients had resolution of a preexisting cranial neuropathy. Data are available in Tables 4 and 5.

We defined disease progression to be an increase in tumor volume of $5 \%$ from the patient's last follow-up visit. 


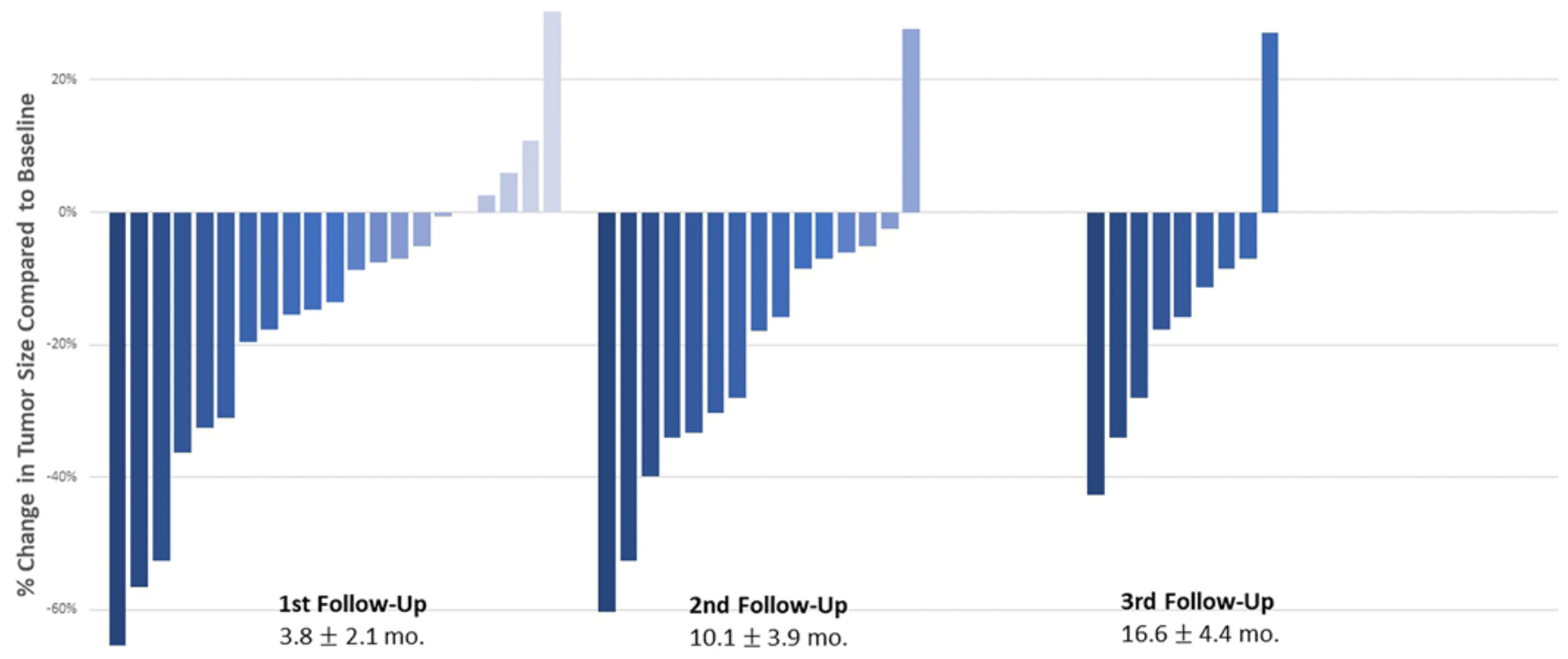

FIG. 2. Change in tumor size compared to baseline for each patient at each of 3 follow-up visits.

Using this threshold, 4 patients had progression throughout the course of their follow-up. Detailed presentation of change in tumor volume from baseline for all tumors and for lesions that progressed according to the aforementioned criteria is available in Fig. 2. PLE was classified in 5 degrees based on radiological features on MRI FLAIR sequences. Only 5 patients had evidence of PLE ( 3 had first degree and 2 had second degree) on pre-GKRS MRI and all of them were asymptomatic. At the first follow-up, there was a slight increase in PLE (first to second degree) in 3 of the patients who previously had first-degree PLE, but they remained asymptomatic and did not require any antiedema measures. However, none of the patients had any evidence of PLE by the final follow-up visit.

\section{Discussion}

Initial management of intracranial meningiomas consists of observation, surgery, radiosurgery/radiotherapy, or a combination of these. Resection is the mainstay of meningioma treatment, especially when complete resection is possible. ${ }^{6,7,30}$ However, SBMs pose a special challenge due to their proximity to one or more critical neurovascular structures, and resection can carry high mortality and morbidity rates.9, ${ }^{927}$ GKRS has proven to be a viable option for achieving tumor control in the management of SBMs, ${ }^{17,20,24,25}$ both in conjunction with surgery and as the primary mode of treatment. ${ }^{11,13,14,29,33}$ In a study of 972 patients, mostly with SBMs treated with GKRS, Kondziolka et al. reported an actuarial tumor control rate of $93 \%, 87 \%$, and $87 \%$ at 5, 10, and 15 years, respectively. ${ }^{24} \mathrm{~A}$ large literature review by Minniti et al. found 18 studies with 1626
SBMs treated with GKRS, with an average 10 -year actuarial control rate of $87.6 \%{ }^{33}$ Neurological improvements rates were noted to be between $8 \%$ and $66 \%$ for most large series. In our own series we found comparable tumor control and neurological improvement rates within the brief follow-up period.

\section{Radiobiological Rationale of Using fGKRS Versus Single-Fraction GKRS}

While single-fraction treatment of small lesions is both effective for controlling tumors and sparing of normal tissue, it can be a considerable challenge to balance tumor control and radiation-induced toxicity for larger tumors. The ability to safely deliver an adequate dose in a single fraction to large tumors is limited when tumor diameters are above $2-3 \mathrm{~cm}$, as was shown in Radiation Therapy Oncology Group (RTOG) trial 9005. ${ }^{39}$ Fractionated GKRS (normally 2-5 sessions) may provide improved balance of tumor control and normal tissue toxicity over single-fraction GKRS, particularly in larger tumors and those next to critical structures. $^{21}$

\section{fGKRS in Large Tumors}

Traditionally, most meningioma series have excluded large-volume tumors, and a diameter of $30-35 \mathrm{~mm}$ was the recommended cutoff for radiosurgery. ${ }^{22,23}$ Several series have noted poor radiosurgery outcomes in patients harboring meningiomas $>8 \mathrm{~cm}$ in maximum diameter. ${ }^{3,13,15,19}$ When treating large tumors with single-fraction GKRS, there is also an increased risk of radiation-induced toxicity. Han et al. reported a series of 28 patients who underwent 
TABLE 6. Previously reported experiences with fGKRS using the Gamma Knife Extend and Icon systems

\begin{tabular}{lcccc}
\hline \multicolumn{1}{c}{ Variable } & Nguyen et al., 2014 & Devriendt et al., 2015 & McTyre et al., 2017 & Present series \\
\hline No. of patients & 15 & 12 & 15 & 25 \\
\hline Median treatment volume (range) in ml & $7.3(1.2-22.7)$ & $6.1(2-17.9)$ & $11.45(0.37-51.81)$ & $8.67(3.23-14.11)$ \\
\hline Median margin dose (range) in Gy & $20(15-25)$ & $25(24-25)$ & 20 & $25(24-25)$ \\
\hline $\begin{array}{l}\text { No. of fractions (dose/fraction) in Gy, } \\
\text { no. (\%) }\end{array}$ & $3-6(40), 4-5(33)$, & $4-1(8), 5-11(92)$ & $4-15(100)$ & $4-2(8), 5-23(92)$ \\
\hline Prior therapy, no. (\%) & $5-4(27)$ & & & - \\
\hline Resection & $7(46.7)$ & $9(75)$ & - & $12(48)$ \\
\hline Single-session SRS & $1(6.7)$ & - & $1(6)$ & - \\
\hline Fractionated radiotherapy & $1(6.7)$ & - & 7.6 & $1(16)$ \\
\hline Average follow-up duration in mos & 17.7 & 19.3 & $3(20)$ & $2(9)$ \\
\hline Radiation adverse effects, no. (\%) & $0(0)$ & $0(0)$ & & 12.4 \\
\hline
\end{tabular}

$-=$ nil.

fGKRS for large meningiomas (volume $>10 \mathrm{~cm}^{3}$ ), treated on the basis of the linear quadratic model. ${ }^{18}$ The median tumor volume was $21 \mathrm{~cm}^{3}$ and the median prescription dose was $7.5 \mathrm{~Gy} / 2$ fractions (range 5-8 Gy), $6 \mathrm{~Gy} / 3$ fractions (range 5-6.5 Gy), and $4.5 \mathrm{~Gy} / 4$ fractions. The fGKRS group had a higher progression-free survival rate at 5 years $(92.9 \%$ vs $88.1 \%$ in the single-session Gamma Knife group). Also, patients receiving multisession GKRS experienced a lower complication rate $33 \%$ in singlefraction treatment, $7.1 \%$ in fGKRS; $p=0.017$, hazard ratio 5.7:1). Park et al. found fractionated radiosurgery using the Gamma Knife Perfexion for large $\left(>10 \mathrm{~cm}^{3}\right)$ SBMs to be safe and effective, with only $17 \%$ of patients experiencing new-onset cranial neuropathy. ${ }^{36}$ The median tumor volume in our series was $7.62 \mathrm{~cm}^{3}$ (range $4.57-13.07 \mathrm{~cm}^{3}$ ) with an overall progression-free survival of $82.5 \%$ at 1 year. Four of these patients were followed up to 40 months and had a median reduction in volume of $30 \%$ ( -39.3 to -12.3$)$.

\section{Cranial Nerve Toxicity}

There is a demonstrated difference in the radiation tolerance of the various cranial nerves, with special sensory nerves (such as optic and cochlear nerves) tolerating the least radiation while the nerves in the parasellar region, the facial nerves, and the lower cranial nerves appear to tolerate a higher dose..$^{41}$ In a multicenter study of sellar/ parasellar meningiomas in which 763 patients were treated with single-fraction GKRS, with a dose cutoff of $13 \mathrm{~Gy}$ and a median follow-up duration of 66.7 months, $9.6 \%$ of patients developed new or worsening cranial nerve deficits. ${ }^{40}$ fGKRS can theoretically circumvent this issue by allowing normal tissues to recover between fractions. Tumors abutting the optic pathway are not typically treated with single-fraction radiosurgery, as it is not possible to treat these tumors to a curative dose while keeping the optic structures constrained within their tolerance dose. With the advent of fractionated radiosurgery, these tumors can now be treated in 4-5 fractions without exceeding the maximum tolerance dose of the optic nerve. ${ }^{42}$ Adler et al. reported on a series of 27 patients with perioptic meningiomas (within $2 \mathrm{~mm}$ of a "short segment" of the optic apparatus), treated with multisession Cyber Knife radio- surgery, to an average margin dose of 20.3 Gy in 2-5 fractions. The local control and vision preservation rate for the cohort was $94 \% .^{1}$ In our series of 25 patients, SBMs were treated to a mean margin dose of 24.9 Gy in $4-5$ fractions. At the first follow-up visit, 2 (9\%) of 22 patients demonstrated new-onset cranial neuropathy, while 6 patients (27\%) demonstrated improvement in cranial neuropathies. No patients developed vision loss.

\section{Perilesional Edema}

During treatment of large intracranial meningiomas, high single doses of radiation may be associated with increased risk of PTE. Kuhn et al. ${ }^{26}$ reported that patients with tumor volumes $>7 \mathrm{~cm}^{3}$ had a 4.9 -fold increase in symptomatic edema compared to patients with tumors that were smaller than $7 \mathrm{~cm}^{3}$. Other risk factors for development of posttreatment edema are the amount of pretreatment edema and the amount of tumor-brain contact interface area. Fractionated radiotherapy has been shown to have a lower risk of symptomatic edema compared to single-fraction radiosurgery. ${ }^{5,45}$ This is very well supported in our series, where a mild increase in PLE developed in only 3 patients, who were asymptomatic and did not require any further treatment.

\section{Advantages of Extend//con}

To the best of our knowledge, there have been only 3 previous institutional experiences reporting the use of the Extend system ${ }^{10,32,34}$ and one description of the Icon system. ${ }^{43}$ The characteristics of the tumors treated with fGKRS in these studies are listed in Table 6. The main limitation of previous Gamma Knife units was the need for repeated or prolonged application of an invasive pinbased stereotactic frame. The relocatable frame system of Gamma Knife Extend and the thermoplastic mask in the Gamma Knife Icon system obviate the need for repeat application or prolonged use of a pin-based system. This could be a great advantage in patients who have had previous craniotomies (12 in our series). The main limitation of the Extend unit is the necessity of having an intact upper palate and dentition to provide adequate support for 
the dental mouthpiece. ${ }^{10}$ Also, the repositioning check tool was quite cumbersome. These limitations are overcome in the Icon, which uses a thermoplastic mask with infrared tracking of the patient's nose marker for the intrafraction motion management system in addition to CBCT image guidance. The accuracy and stability of this system have also been validated in a preclinical prospective study. ${ }^{28}$ However, a recent retrospective study from the Rutgers Cancer Institute showed mask fixation demonstrated significantly larger intrafraction errors than frame fixation. Also, there was greater variability in both setup and intrafraction errors for mask fixation than for frame fixation in all translational and rotational directions. ${ }^{4}$ The variability in motion error associated with mask fixation must be taken into account when planning for small lesions or lesions near critical structures.

\section{Limitations}

Our study is one of the largest radiosurgical series of fGKRS treatment of SBMs to date. However, this study is limited by its retrospective nature and its institutional and treatment biases. Additionally, this study does not compare treatment of SBMs with fGKRS versus single-session GKRS or fractionated stereotactic radiotherapy. The short follow-up period does not allow us to make definitive statements on actuarial control, and even though we used volumetric measurements (which is considered a more robust metric to measure change in tumor size), we acknowledge that our threshold for tumor progression deviates from the more traditional linear criteria of $>20 \% .^{12}$ However, this was deliberately done to pick up early progression/interval change and remove any confounding effect of the short follow-up period. Further assessment of large cohorts, followed for a longer period of time, may be required to fully define the treatment efficacy of fGKRS and the long-term neurological outcome. Finally, the safety and efficacy of fGKRS needs to be compared to fractionated radiotherapy, which has been historically considered the standard treatment for meningiomas that are large or abutting sensitive structures.

\section{Conclusions}

The development of a reproducible immobilization system in the Gamma Knife Extend and the subsequent introduction of the thermoplastic mask immobilization system in the Gamma Knife Icon have simplified multisession GKRS and increased the number of indications. They are especially useful to overcome the dose limitation in large SBMs close to critical neurovascular structures.

\section{References}

1. Adler JR Jr, Gibbs IC, Puataweepong P, Chang SD: Visual field preservation after multisession CyberKnife radiosurgery for perioptic lesions. Neurosurgery 59:244-254, 2006

2. Benedict SH, Yenice KM, Followill D, Galvin JM, Hinson W, Kavanagh B, et al: Stereotactic body radiation therapy: the report of AAPM Task Group 101. Med Phys 37:4078-4101, 2010 (Erratum in Med Phys 39:563, 2012)

3. Bledsoe JM, Link MJ, Stafford SL, Park PJ, Pollock BE: Radiosurgery for large-volume $\left(>10 \mathrm{~cm}^{3}\right)$ benign meningiomas. J Neurosurg 112:951-956, 2010
4. Carminucci A, Nie K, Weiner J, Hargreaves E, Danish SF: Assessment of motion error for frame-based and noninvasive mask-based fixation using the Leksell Gamma Knife Icon radiosurgery system. J Neurosurg 129 (Suppl 1):133-139, 2018

5. Colombo F, Casentini L, Cavedon C, Scalchi P, Cora S, Francescon P: Cyberknife radiosurgery for benign meningiomas: short-term results in 199 patients. Neurosurgery 64 (2 Suppl):A7-A13, 2009

6. Condra KS, Buatti JM, Mendenhall WM, Friedman WA, Marcus RB Jr, Rhoton AL: Benign meningiomas: primary treatment selection affects survival. Int J Radiat Oncol Biol Phys 39:427-436, 1997

7. Davidson L, Fishback D, Russin JJ, Weiss MH, Yu C, Pagnini PG, et al: Postoperative Gamma Knife surgery for benign meningiomas of the cranial base. Neurosurg Focus 23(4):E6, 2007

8. DeMonte F: Surgical treatment of anterior basal meningiomas. J Neurooncol 29:239-248, 1996

9. DeMonte F, Smith HK, Al-Mefty O: Outcome of aggressive removal of cavernous sinus meningiomas. J Neurosurg 81:245-251, 1994

10. Devriendt D, De Smedt F, Glineur R, Massager N: Five-fraction Gamma Knife radiosurgery using the Extend relocatable system for benign neoplasms close to optic pathways. Pract Radiat Oncol 5:e119-e125, 2015

11. DiBiase SJ, Kwok Y, Yovino S, Arena C, Naqvi S, Temple $\mathrm{R}$, et al: Factors predicting local tumor control after gamma knife stereotactic radiosurgery for benign intracranial meningiomas. Int J Radiat Oncol Biol Phys 60:1515-1519, 2004

12. Eisenhauer EA, Therasse P, Bogaerts J, Schwartz LH, Sargent D, Ford R, et al: New response evaluation criteria in solid tumours: revised RECIST guideline (version 1.1). Eur J Cancer 45:228-247, 2009

13. Flannery TJ, Kano H, Lunsford LD, Sirin S, Tormenti M, Niranjan A, et al: Long-term control of petroclival meningiomas through radiosurgery. J Neurosurg 112:957-964, 2010

14. Flickinger JC, Kondziolka D, Maitz AH, Lunsford LD: Gamma knife radiosurgery of imaging-diagnosed intracranial meningioma. Int J Radiat Oncol Biol Phys 56:801-806, 2003

15. Ganz JC, Reda WA, Abdelkarim K: Gamma Knife surgery of large meningiomas: early response to treatment. Acta Neurochir (Wien) 151:1-8, 2009

16. Hall EJ, Giaccia AJ: Molecular mechanisms of DNA and chromosome damage and repair, in Radiobiology for the Radiologist, ed 7. Philadelphia: Lippincott Williams \& Wilkins, 2012, pp 12-34

17. Han JH, Kim DG, Chung HT, Park CK, Paek SH, Kim CY, et al: Gamma knife radiosurgery for skull base meningiomas: long-term radiologic and clinical outcome. Int J Radiat Oncol Biol Phys 72:1324-1332, 2008

18. Han MS, Jang WY, Moon KS, Lim SH, Kim IY, Jung TY, et al: Is fractionated Gamma Knife radiosurgery a safe and effective treatment approach for large-volume $\left(>10 \mathrm{~cm}^{3}\right)$ intracranial meningiomas? World Neurosurg 99:477-483, 2017

19. Haselsberger K, Maier T, Dominikus K, Holl E, Kurschel S, Ofner-Kopeinig P, et al: Staged gamma knife radiosurgery for large critically located benign meningiomas: evaluation of a series comprising 20 patients. J Neurol Neurosurg Psychiatry 80:1172-1175, 2009

20. Igaki H, Maruyama K, Koga T, Murakami N, Tago M, Terahara A, et al: Stereotactic radiosurgery for skull base meningioma. Neurol Med Chir (Tokyo) 49:456-461, 2009

21. Kirkpatrick JP, Soltys SG, Lo SS, Beal K, Shrieve DC, Brown PD: The radiosurgery fractionation quandary: single fraction or hypofractionation? Neuro Oncol 19 (Suppl 2):ii38-ii49, 2017

22. Kondziolka D, Lunsford LD: Radiosurgery of meningiomas. Neurosurg Clin N Am 3:219-230, 1992 
23. Kondziolka D, Lunsford L, Linskey M, Flickinger J: Skull base radiosurgery, in Alexander E III, Loeffler JS, Lunsford LD (eds): Stereotactic Radiosurgery. New York: McGraw Hill, 1993, pp 175-188

24. Kondziolka D, Mathieu D, Lunsford LD, Martin JJ, Madhok R, Niranjan A, et al: Radiosurgery as definitive management of intracranial meningiomas. Neurosurgery 62:53-60, 2008

25. Kreil W, Luggin J, Fuchs I, Weigl V, Eustacchio S, Papaefthymiou G: Long term experience of gamma knife radiosurgery for benign skull base meningiomas. J Neurol Neurosurg Psychiatry 76:1425-1430, 2005

26. Kuhn EN, Taksler GB, Dayton O, Loganathan A, Bourland $\mathrm{D}$, Tatter SB, et al: Is there a tumor volume threshold for postradiosurgical symptoms? A single-institution analysis. Neurosurgery 75:536-545, 2014

27. Larson JJ, van Loveren HR, Balko MG, Tew JM Jr: Evidence of meningioma infiltration into cranial nerves: clinical implications for cavernous sinus meningiomas. J Neurosurg 83:596-599, 1995

28. Li W, Bootsma G, Von Schultz O, Carlsson P, Laperriere N, Millar BA, et al: Preliminary evaluation of a novel thermoplastic mask system with intra-fraction motion monitoring for future use with image-guided Gamma Knife. Cureus 8:e531, 2016

29. Linskey ME, Davis SA, Ratanatharathorn V: Relative roles of microsurgery and stereotactic radiosurgery for the treatment of patients with cranial meningiomas: a single-surgeon 4-year integrated experience with both modalities. J Neurosurg 102 Suppl:59-70, 2005

30. Maire JP, Caudry M, Guérin J, Célérier D, San Galli F, Causse N, et al: Fractionated radiation therapy in the treatment of intracranial meningiomas: local control, functional efficacy, and tolerance in 91 patients. Int J Radiat Oncol Biol Phys 33:315-321, 1995

31. Marchetti M, Bianchi S, Milanesi I, Bergantin A, Bianchi L, Broggi G, et al: Multisession radiosurgery for optic nerve sheath meningiomas - an effective option: preliminary results of a single-center experience. Neurosurgery 69:11161123,2011

32. McTyre E, Helis CA, Farris M, Wilkins L, Sloan D, Hinson WH, et al: Emerging indications for fractionated Gamma Knife radiosurgery. Neurosurgery 80:210-216, 2017

33. Minniti G, Amichetti M, Enrici RM: Radiotherapy and radiosurgery for benign skull base meningiomas. Radiat Oncol 4:42, 2009

34. Nguyen JH, Chen CJ, Lee CC, Yen CP, Xu Z, Schlesinger D, et al: Multisession gamma knife radiosurgery: a preliminary experience with a noninvasive, relocatable frame. World Neurosurg 82:1256-1263, 2014

35. Oermann EK, Bhandari R, Chen VJ, Lebec G, Gurka M, Lei $\mathrm{S}$, et al: Five fraction image-guided radiosurgery for primary and recurrent meningiomas. Front Oncol 3:213, 2013

36. Park HR, Lee JM, Park KW, Kim JH, Jeong SS, Kim JW, et al: Fractionated Gamma Knife radiosurgery as initial treatment for large skull base meningioma. Exp Neurobiol 27:245-255, 2018

37. Sayer FT, Sherman JH, Yen CP, Schlesinger DJ, Kersh R, Sheehan JP: Initial experience with the eXtend System: a relocatable frame system for multiple-session gamma knife radiosurgery. World Neurosurg 75:665-672, 2011

38. Sekhar LN, Swamy NK, Jaiswal V, Rubinstein E, Hirsch WE Jr, Wright DC: Surgical excision of meningiomas involving the clivus: preoperative and intraoperative features as predictors of postoperative functional deterioration. J Neurosurg 81:860-868, 1994
39. Shaw E, Scott C, Souhami L, Dinapoli R, Kline R, Loeffler J, et al: Single dose radiosurgical treatment of recurrent previously irradiated primary brain tumors and brain metastases: final report of RTOG protocol 90-05. Int J Radiat Oncol Biol Phys 47:291-298, 2000

40. Sheehan JP, Starke RM, Kano H, Kaufmann AM, Mathieu D, Zeiler FA, et al: Gamma Knife radiosurgery for sellar and parasellar meningiomas: a multicenter study. J Neurosurg 120:1268-1277, 2014

41. Sheehan JP, Williams BJ, Yen CP: Stereotactic radiosurgery for WHO grade I meningiomas. J Neurooncol 99:407-416, 2010

42. Shrieve DC, Hazard L, Boucher K, Jensen RL: Dose fractionation in stereotactic radiotherapy for parasellar meningiomas: radiobiological considerations of efficacy and optic nerve tolerance. J Neurosurg 101 (Suppl 3):390-395, 2004

43. Stieler F, Wenz F, Abo-Madyan Y, Schweizer B, Polednik M, Herskind C, et al: Adaptive fractionated stereotactic Gamma Knife radiotherapy of meningioma using integrated stereotactic cone-beam-CT and adaptive re-planning (a-gkFSRT). Strahlenther Onkol 192:815-819, 2016

44. Torres RC, Frighetto L, De Salles AA, Goss B, Medin P, Solberg T, et al: Radiosurgery and stereotactic radiotherapy for intracranial meningiomas. Neurosurg Focus 14(5):e5, 2003

45. Unger KR, Lominska CE, Chanyasulkit J, Randolph-Jackson P, White RL, Aulisi E, et al: Risk factors for posttreatment edema in patients treated with stereotactic radiosurgery for meningiomas. Neurosurgery 70:639-645, 2012

46. Wiemels J, Wrensch M, Claus EB: Epidemiology and etiology of meningioma. J Neurooncol 99:307-314, 2010

\section{Disclosures}

Dr. Chao reports receiving an honorarium from Varian Medical Systems. Dr. Neyman reports being a consultant for Elekta AB.

\section{Author Contributions}

Conception and design: Angelov, Joshi. Acquisition of data: Joshi, Raghavan, Muhsen. Analysis and interpretation of data: Angelov, Joshi, Raghavan, Muhsen, Hsieh, Borghei-Razavi, Chao, Barnett. Drafting the article: Angelov, Joshi, Raghavan, Muhsen. Critically revising the article: Angelov, Joshi, Muhsen, Hsieh, Borghei-Razavi, Chao, Barnett, Suh, Neyman, Kshettry, Recinos, Mohammadi. Reviewed submitted version of manuscript: all authors. Approved the final version of the manuscript on behalf of all authors: Angelov. Statistical analysis: Joshi, Raghavan, Muhsen, Hsieh. Administrative/technical/material support: Angelov, Joshi, Borghei-Razavi, Chao, Barnett, Suh, Neyman. Study supervision: Angelov, Joshi, Chao, Barnett, Suh.

\section{Correspondence}

Lilyana Angelov: The Rose Ella Burkhardt Brain Tumor and Neuro-Oncology Center, Neurological and Taussig Cancer Institute, Cleveland Clinic, Cleveland, OH. angelol@ccf.org. 